Relations industrielles

Industrial Relations

\title{
La C.T.C.C. et la fusion
}

Volume 10, numéro 4, septembre 1955

URI : https://id.erudit.org/iderudit/1022674ar

DOI : https://doi.org/10.7202/1022674ar

Aller au sommaire du numéro

\section{Éditeur(s)}

Département des relations industrielles de l’Université Laval

\section{ISSN}

0034-379X (imprimé)

1703-8138 (numérique)

Découvrir la revue

\section{Citer ce document}

(1955). La C.T.C.C. et la fusion. Relations industrielles / Industrial Relations, 10(4), 294-294. https://doi.org/10.7202/1022674ar
Résumé de l'article

$\mathrm{Au}$ Congrès de la Confédération des Travailleurs Catholiques du Canada en septembre dernier, le président M. Gérard Picard émettait, dans les lignes suivantes de son rapport, son opinion sur l'unité syndicale organique.
Tous droits réservés @ Département des relations industrielles de l’Université Laval, 1955
Ce document est protégé par la loi sur le droit d'auteur. L’utilisation des services d'Érudit (y compris la reproduction) est assujettie à sa politique d'utilisation que vous pouvez consulter en ligne.

https://apropos.erudit.org/fr/usagers/politique-dutilisation/ 
(d) Après ratification par les conventions distinctes des deux Congrès, le comité d'unité est autorisé à appeler une convention conjointe selon les dispositions de la section 2 de ce mémoire. Cette convention conjointe constituera la première convention biennale du Congrès fusionné, au cours de laquelle le projet de constitution sera étudié et adopté.

\section{La C.T.C.C. et la fusion}

\section{Au Congrès de la Confédération des Travailleurs Catholiques du Canada en septembre dernier, le président M. Gérard Picard émettait, dans les lignes suivantes de son rapport, son opinion sur l'unité syndi- cale organique.}

Une autre question qui court sur toutes les lèvres, et dont il a été question précédemment. est celle qui a trait à l'unité syndicale organique dans ses conséquences sur la C.T.C.C. Dans l'intérêt des travailleurs qu'elle représente et dans l'intérèt des travailleurs canadiens en général, la C.T.C.C. doit-elle demeurer une centrale syndicale indépendante des autres centrales, ou devrait-elle, par affiliation ou disparition, s'intégrer dans l'unité syndicale organique nord-américaine? La question est d'actualité sans doute, mais elle n'est pas pressante au point qu'elle exige une réponse du Congrès dès cette année. Nous savons, il est vrai, que l'AFL et le CIO, aux Etats-Unis, se fusionneront prochainement, et que, un peu plus tard, le CMTC et le CCT se fusionneront au Canada. Par ailleurs, la C.T.C.C. n'a reçu, à date, aucune invitation officielle de participer à l'unité syndicale organique ni d'engager des pourparlers à ce sujet. De plus, les discussions préléminaires qui ont eu lieu au sein de la C.T.C.C., au cours de l'année, révèlent que la question n'est pas encore suffisamment mûrie même si un certain nombre de dirigeants et de militants paraissent prèts à examiner des opinions bien arrêtées sur les divers aspects du problème. La C.T.C.C. y gagnerait à continuer l'examen de cette question une autre année avant de prendre une position définitive. Si le Congrès le désire, il peut nommer une commission spéciale dont la préoccupation sera d'examiner la question sous tous ses angles et de faire rapport au prochain Cungrès.

\section{A STATEMENT ON INDUSTRIAL RELATIONS BY THE CANADIAN MANUFACTURERS' ASSOCIATION}

The Canadian Manufacturers' Association believes that the prime function of industry is to supply consumers with satisfactory goods at prices which will encourage a high level of consumption.

The Association believes that the following conditions are essential to the successful performance of this function and to the healthy growth of free enterprise industry:

1. Suitable plant, equipment and machinery with sound management and an efficient work force. 